\title{
HUBUNGAN STATUS PEKERJAAN DAN PENDAPATAN DENGAN PEMANFAATAN PUSKESMAS SEBAGAI PELAYANAN PRIMER DI PUSKESMAS SIDOMULYO
}

\section{RELATIONSHIP OF EMPLOYMENT STATUS AND INCOME WITH UTILIZATION OF PUBLIC HEALTH CENTER AS PRIMARY SERVICES IN PUBLIC HEALTH CENTER OF SIDOMULYO}

\author{
Oleh: \\ Oktarianita ${ }^{1}$, Andry Sartika ${ }^{2}$, Nopia Wati ${ }^{3}$ \\ 1,2,3 Prodi Kesehatan Masyarakat, Fakutas IImu Kesehatan \\ Universitas Muhammadiyah Bengkulu \\ 1,2,3J. H. Adam Malik Km 8,5 Cempaka Permai Kota Bengkulu \\ Email: oktarianita@umb.ac.id
}

\begin{abstract}
Utilization of public health center is an effort to improve health status. it is known that the number of referrals from the public health center of Sidomulyo to the hospital reached 617 cases, indicating the high need for the public health center to utilization. The purpose of this study was to determine the relationship between employment status and income with the utilization of health services at public health center of Sidomulyo.. This research is a quantitative study, with a cross sectional design using accidental sampling technique which was carried out during May-June 2021. The population was all people in the working area of the public health center of Sidomulyo, with a sample of 50 respondents. The data were analyzed using the SPSS 16 application, the data analyzed were univariate, bivariate tests. The results of univariate analysis showed that the respondents who had used health services were 40 people (80\%), working 37 people (74\%) and respondents who had an income of 2,000,000 as many as 27 people (54\%). Variables related to the utilization of the public health center as primary care at the public health center of Sidomulyo were occupation $(p=0.046)$, while there was no relationship between income ( $p>)$. It is hoped that the public health center will continue to disseminate information regarding existing health services as an effort to increase utilization.
\end{abstract}

Keywords: Employment, Utilization of Public Health Center, Income

\begin{abstract}
ABSTRAK
Pemanfaatan Puskesmas merupakan upaya dalam meningkatkan derajat kesehatan. Diketahui bahwa jumlah rujukan dari Puskesmas Sidomulyo ke rumah sakit mencapai 617 kasus, menunjukkan tingginya kebutuhan masyarakat dalam pemanfaatan Puskesmas tersebut. Tujuan penelitian ini adalah untuk mengetahui hubungan status pekerjaan dan pendapatan dengan pemanfaatan pelayanan kesehatan di Puskesmas Sidomulyo. Penelitian ini merupakan penelitian kuantitatif, dengan rancangan Cross Sectional menggunakan teknik accidental sampling yang dilaksanakan selama bulan Mei 2021. Populasi adalah seluruh masyarakat di wilayah kerja Puskesmas Sidomulyo kota Bengkulu dengan sampel sebanyak 50 responden. Data di analisis dengan menggunakan aplikasi SPSS 16, data yang di analisis adalah uji univariat, bivariat. Hasil analisis univariat menunjukkan bahwa responden telah memanfaatkan pelayanan kesehatan yaitu 40 orang (80\%), bekerja 37 orang $(74 \%)$ dan responden yang mempunyai pendapatan $\leq 2.000 .000$ sebanyak 27 orang $(54 \%)$. Variabel yang berhubungan dengan pemanfaatan Puskesmas sebagai pelayanan primer di puskesmas Sidomulyo adalah pekerjaan $(p=0,046)$, sedangkan pendapatan tidak terdapat hubungan (nilai $p>\alpha$ ). Diharapkan pihak Puskesmas untuk terus melakukan sosialisasi terkait pelayanan kesehatan yang ada sebagai upaya peningkatan pemanfaatan.
\end{abstract}


Kata kunci : Pekerjaan, Pemanfaatan Puskesmas, Pendapatan

\section{PENDAHULUAN}

Penguatan pelayanan kesehatan dasar (primary health care) yang berkualitas merupakan hal yang menjadi fokus dalam kebijakan pembangunan kesehatan. Upaya tersebut dilakukan melalui peningkatan akses, peningkatan jaminan kesehatan, peningkatan mutu dalam pelayanan kesehatan dasar dan rujukan serta memperkuat sistem kesehatan dan peningkatan dalam pembiayaan kesehatan (Kemenkes RI, 2015).

Puskesmas merupakan fasilitas pelayanan kesehatan yang menyelenggarakan upaya kesehatan masyarakat dan upaya kesehatan perorangan tingkat pertama, dengan lebih mengedepankan upya promotif dan preventif untuk meningkatkan derajat kesehatan masyarakat yang setinggi-tingginya (Kemenkes RI, 2014).

Suatu layanan kesehatan akan dianggap memuaskan jika harapan pasien dapat terpenuhi sehingga timbul keinginan dari pasien untuk kembali berkunjung ke pelayanan kesehatan. Salah satunya dari dimensi tangible yaitu berupa Kemudahan mencapai lokasi Puskesmas (Febriawati $\mathrm{H}$ et al., 2021).

Puskesmas mempunyai peran dan fungsi yang bertujuan meningkatkan derajat kesehatan masyarakat dan menyelenggarakan pelayanan kesehatan yang terintegrasi pada semua kegiatan promotif, preventif dan kuratif Febriawati, H. 2019). Namun saat ini Puskesmas masih kurang dimanfaatkan oleh masyarakat.

Pemanfaatan pelayanan kesehatan dipengaruhi beberapa faktor di antaranya sarana atau alat Puskesmas yang masih kurang, aksesbilitas, sikap petugas, kesadaran masyarakat, kurangnya minat masyarakat untuk memanfaatkan pelayanan kesehatan di Puskesmas disebabkan juga karena seseorang tidak memiliki pekerjaan tetap hal ini berdampak pada pendapatan yang diperoleh rendah.

Faktor Predisposisi (jenis kelamin,

umur, status perkawinan, pendidikan, pekerjaan, suku, dan kepercayaan kesehatan), karakteristik kemampuan (penghasilan, asuransi, kemampuan membeli jasa pelayanan kesehatan, pengetahuan tentang kebutuhan pelayanan kesehatan, adanya sarana pelayanan kesehatan, waktu tunggu pelayanan serta aksesibilitasnya dan ketersediaan tenaga kesehatan), dan karakteristik kebutuhan (penilaian individu, dan penilaian klinik terhadap suatu penyakit) menjadi tiga faktor yang dapat memperngaruhi pemanfaatan pelayanan kesehatan. Setiap faktor tersebut kemungkinan berpengaruh sehingga dapat untuk memprediksi pemanfaatan pelayanan kesehatan (Fatimah Siti \& Indrawati Fitri, 2019).

Tingkat pendapatan yang memadai bisa memberikan kemungkinan yang lebih besar dapat memanfaatkan fasilitas kesehatan untuk melakukan pemeriksaan diri dan mengambil obat (Febriawati Henni \& Yandrizal, 2019).

Puskesmas Sidomulyo merupakan salah satu puskesmas yang ada di kota Bengkulu terletak di jalan Hibrida VII kecamatan Gading Cempaka dengan luas wilayah $3 \mathrm{~km}^{2}$ dan memiliki jumlah penduduk mencapai 11.067 orang dan 3.188 KK (Data Laporan Penduduk, 2021).

Hasil observasi awal diketahui puskesmas Sidomulyo memiliki pelayanan kesehatan meliputi dokter umum, dokter gigi, pelayanan kesehatan lingkungan, pelayanan kesehatan gigi dan mulut, pelayanan kesehatan Usia Lanjut (USILA), pelayanan kesehatan masyarakat, gizi, farmasi seperti apotek, posyandu KIA dan pelayanan kesehatan rujukan dan penunjanng. Jumlah rujukan ke rumah sakit mencapai 617 kasus hal ini Puskesmas Sidomulyo banyak mendapat limpahan dari kabupaten dikarenakan Puskesmas dekat dengan rumah sakit rujukan (Kemenkes RI, 2020).

Berdasarkan latar belakang tersebut, maka peneliti tertarik untuk melakukan penelitian mengenai hubungan status pekerjaan dan pendapatan dengan pemanfaatan Puskesmas sebagai pelayanan primer.

\section{METODE PENELITIAN}

Penelitian ini merupakan penelitian kuantitatif dengan rancangan Cross Sectional. 
Pengumpulan data menggunakan data primer dengan cara membagikan kuesioner kepada responden yang berisi pertanyaan, menggunakan teknik accidental sampling yang dilaksanakan selama bulan Mei-Juni 2021. Populasi adalah seluruh masyarakat di wilayah kerja Puskesmas Sidomulyo kota Bengkulu dengan sampel sebanyak 50 responden. Data di analisis dengan menggunakan aplikasi SPSS 16, data yang di analisis adalah uji univariat, bivariat melihat variabel (status pekerjaan dan pendapatan responden) yang berhubungan dengan pemanfaatan pelayanan kesehatan.

\section{HASIL PENELITIAN}

\section{Analisis Univariat}

Tabel 1. Distribusi Frekuensi Variabel berdasarkan pemanfaatan puskesmas, status pekerjaan dan pendapatan

\begin{tabular}{ccc}
\hline Variabel & Jumlah & $\begin{array}{c}\text { Persen } \\
(\%)\end{array}$ \\
\hline $\begin{array}{c}\text { Pemanfaatan } \\
\text { Puskesmas }\end{array}$ & & \\
$\begin{array}{c}\text { Tidak } \\
\text { Memanfaatkan }\end{array}$ & 10 & 20 \\
Memanfaatkan & 40 & 80 \\
\hline $\begin{array}{c}\text { Status } \\
\text { Pekerjaan }\end{array}$ & & \\
\hline Bekerja & 37 & 74 \\
Tidak Bekerja & 13 & 26 \\
\hline Pendapatan & & \\
\hline$>2.000 .000$ & 23 & 46 \\
$\leq 2.000 .000$ & 27 & 54 \\
\hline Total & 50 & $100 \%$ \\
\hline
\end{tabular}

Pada tabel 1. hasil analisis univariat yaitu, dari 50 responden diperoleh hasil 40 orang $(80 \%)$ sudah memanfaatkan puskesmas. Sebanyak 37 orang $(74 \%)$ responden yang bekerja dan sebanyak 27 orang $(54 \%)$ responden yang mendapatkan pendapatan $\leq 2.000 .000$.

\section{Analisis Bivariat}

Tabel 2. Hubungan Pekerjaan dan Pendapatan dengan Pemanfaatan Puskesmas Sebagai Pelayanan Primer di Puskesmas Sidomulyo Kota Bengkulu

\begin{tabular}{|c|c|c|c|c|c|c|}
\hline \multirow{3}{*}{ Variabel-variabel } & \multicolumn{4}{|c|}{ Pemanfaatan Puskesmas } & \multirow{3}{*}{$\begin{array}{c}\text { PR } \\
(95 \% \text { Cl) }\end{array}$} & \multirow{3}{*}{$P$ value } \\
\hline & \multicolumn{2}{|c|}{$\begin{array}{c}\text { Tidak } \\
\text { Memanfaatkan }\end{array}$} & \multicolumn{2}{|c|}{ Memanfaatkan } & & \\
\hline & $\mathrm{n}$ & $\%$ & $\mathbf{N}$ & $\%$ & & \\
\hline \multicolumn{7}{|l|}{ Status Pekerjaan } \\
\hline Bekerja & 10 & 27 & 27 & 73 & 0,730 & \\
\hline Tidak Bekerja & 0 & 0 & 13 & 100 & $0,6-0,888$ & 0,046 \\
\hline \multicolumn{7}{|l|}{ Pendapatan } \\
\hline$>2.000 .000$ & 7 & 30,4 & 16 & 69,6 & 3,5 & \\
\hline$\leq 2.000 .000$ & 3 & 11,1 & 24 & 88,9 & $0,786-15,578$ & 0,155 \\
\hline
\end{tabular}

Berdasarkan tabel 2. Diketahui bahwa responden yang bekerja lebih banyak memanfaatkan pelayanan puskesmas yaitu 27 orang $(73 \%)$. Hasil analisis bivariat dengan menggunakan aplikasi SPSS 16.0 diperoleh hasil PR $\quad(95 \% \quad \mathrm{Cl}=0,730, \quad 0,6-0,888$ dengan $p$ value $=0,046$ maka dapat disimpulkan ada hubungan antara status pekerjaan dengan pemanfaatan puskesmas. Hasil penelitian terhadap pendapatan responden menunjukkan bahwa responden yang mendapatkan pendapatan $\leq 2.000 .000$ sebagian besar memanfaatkan puskesmas yaitu 24 orang $(88,9 \%)$ Hasil uji analisis bivariat diketahui PR $(95 \%$ $\mathrm{Cl}=3,5,0,786-15,578 ; p$ value $=0,155$ yang berarti tidak ada hubungan antara pendapatan dengan pemanfaatan puskesmas. 
PEMBAHASAN

\section{Hubungan Status Pekerjaan Dengan Pemanfaatn Puskesmas Sebagai Pelayanan Primer}

Hasil penelitian diperoleh data responden yang bekerja memiliki peluang lebih besar memanfaatkan puskesmas dibandingkan responden yang tidak bekerja dan hasil analisis bivariat menunjukkan ada hubungan antara Status Pekerjaan dengan Pemanfaatan Puskesmas Sebagai Pelayanan Primer.

Hasil menunjukkan ada hubungan dengan pemanfaatan Puskesmas. Hal ini di dukung dari data hasil penelitian masyarakat yang bekerja cenderung tidak bisa memanfaatkan pelayanan kesehatan puskesmas dikarenakan bekerja di pagi hingga sore hari, sedangkan pelayanan puskesmas sudah tutup ketika mereka pulang bekerja.

Sejalan dengan hasil peneltian Rabbaniyah \& Nadjib (2019) diketahui terdapat pengaruh signifikan pekerjaan responden untuk memanfaatan fasilitas kesehatan $(p-$ value $<0,1)$. Selaras dengan hasil penelitian Wulandari \& Achadi (2017), menunjukkan pekerjaan berhubungan dengan pemanfaatan Puskesmas sebagai gatekeeper. Responden yang bekerja mengalami kesulitan menggunakan pelayanan di Puskesmas dikarenakan jam pelayanan bersamaan dengan jam kerja.

Selaras dengan hasil penelitian Londo Jenry $P$ et al., (2017) dari hasil analisis diperoleh nilai $p=$ $0,031<\alpha=0,05$. Yang berarti ada Hubungan antara Pekerjaan dengan Pemanfaatan Pelayanan Puskesmas Tahuna Barat.

Salah satu faktor sosio-ekonomi konsumen yang mempengaruhi dalam pelayanan kesehatan adalah pekerjaan (Syarifain et al., 2017). Seseorang yang memiliki pekerjaan akan cenderung untuk memanfaatkan pelayanan kesehatan karena repsonden yang berrpenghasilan memiliki kecenderungan untuk membiayai layanan kesehatan.

Pekerjaan adalah salah satu faktor struktur sosial dalam teori Health System Models dapat memberikan dorongan kepada seseorang dalam mengambil tindakan untuk kesehatannya (Notoatmodjo, 2012).

Ketika masyarakat atau pasien datang ke Puskesmas, ada harapan-harapan pasien terhadap kualitas layanan kesehatan dan kepuasan pasien dengan penyedia layanan (Febriawati $\mathrm{H}$ et al., 2021).

Seseorang yang bekerja namun tetap bisa memanfaatkan pelayanan kesehatan bisa dikarenakan adanya dorongan yang membuat mereka memutuskan untuk memperhatikan kesehatannya disela waktu sibuk mereka bekerja.

\section{Hubungan Pendapatan Dengan Pemanfaatan Puskesmas Sebagai Pelayanan Primer}

Hasil penelitian dapat dilihat responden yang pendapatan $\leq 2.000 .000$ banyak memanfaatkan puskesmas, hasil penelitian juga menunjukkan bahwa repsonden yang memiliki pendapatan $\leq 2.000 .000$ memiliki peluang lebih besar untuk memanfaatkan puskesmas dibandingkan yang berpendapatan $>2.000 .000$. Hasil analisis bivariat diperoleh nilai $p>a$ maka dapat disimpulkan bahwa tidak ada hubungan pendapatan Dengan Pemanfaatn Puskesmas Sebagai Pelayanan Primer.

Hasil penelitian selaras dengan penelitian yang dilakukan Siswati, A. N, et al., (2018), berdasarkan analisis bivariat, kelompok yang belum melakukan imunisasi lebih tinggi kategori pendapatan lebih dari UMR yaitu $70.7 \%$ dibandingkan yang kurang dari UMR. Hasil uji statistik dengan Chi-Square diperoleh nilai $p=0.833$ sehingga dapat disimpulkan bahwa tidak ada hubungan antara pendapatan dengan pemanfaatan pelayanan imunisasi pentavalen booster.

Didukung hasil penelitian Logen, Y., \& Balqis, D. (2015), dilihat dari rata-rata penghasilan responden per bulan didapatkan bahwa responden yang berpenghasilan tinggi lebih banyak memanfaatkan pelayanan kesehatan dibandingkan dengan yang berpenghasilan rendah hal ini dikarenakan responden yang berpenghasilan tinggi mereka masih bisa menggunakan sebagian kecil penghasilannya untuk memeriksakan kesehatan di fasilitas kesehatan yang telah disediakan berbeda dengan yang memiliki 7 penghasilan rendah mereka beranggapan jika penghasilan mereka disimpan untuk hal yang dianggap jauh lebih penting. Tidak ada hubungan antara penghasilan dengan pemanfaatan pelayanan kesehatan.

Pendapatan merupakan seluruh penerimaan 
yang diperoleh dari hasil berkerja dapat berupa uang maupun barang dari tempat ia berkerja ataupun hasil sendiri, di nilai uang atas harga yang berlaku.

Hasil penelitian Napirah Ryman, Rahman Abd (2016) menunjukkan bahwa responden yang memiliki pendapatan keluarga yang tinggi dan tidak memanfaatkan pelayanan kesehatan sebesar $10,5 \%$. Hal ini disebabkan masyarakat mengetahui bahwa untuk mendapatkan pelayanan kesehatan yang bermutu dengan cara membayar. Masyarakat menilai tentang pelayanan kesehatan gratis masih kurang baik akan berdampak pada pemanfaatan pelayanan yang rendah, masyarakat yang memiliki pendapatan keluarga tinggi lebih memilih untuk berkunjung ke tempat pelayanan kesehatan yang mereka anggap lebih baik, seperti rumah sakit atau dokter praktek yang jaraknya lebih jauh dari Puskesmas Tambarana yang terletak di desa tempat mereka tinggal.

Faktor tingkat pendapatan mempengaruhi dalam segi pembiayaan yaitu dalam pembiayaan dipuskesmas, di saat penebusan obat setelah konsultasi tentang penyakit yang diderita. Semakin rendah tingkat pendapatan suatu keluarga makasemakin sulit mengakses pelayanan kesehatan yang baik (Wulandari C, et al., 2016).

Pendapatan yang dimiliki akan berdampak pada penentuan pembiayaan kesehatan. harga pelayanan kesehatan yang terjangkau akan membuat masyarakat untuk memanfaatkan pelayanan tersebut. Bagi pasien, place merupakan kenyamanan atau kemudahan pasien untuk melakukan akses dan memperoleh layanan yang terkait dengan lokasi yang strategis, fasilitas, sistem rujukan dan lainnya Oktarianita, O., et al (2020).

Menurut Rahimah, et., al (2021) bahwa Ketidakpuasan masyarakat terhadap pelayanan sangat dipengaruhi oleh mutu layanan yang diberikan. Adapun faktor lain yang berhubungan dengan kepuasan pasien tersebut seperti: faktor emosional, faktor harga, faktor situasi, faktor pribadi pasien, faktor biaya dan kemudahan

\section{UCAPAN TERIMA KASIH}

Terima kasih peneliti sampaikan kepada Kemenristekdikti/ BRIN atas bantuan dana penelitian dosen pemula dan pihak puskesmas yang telah memfasilitas kegiatan penelitian.

\section{KESIMPULAN}

Berdasarkan hasil penelitian dan pembahasan maka dapat disimpulkan bahwa terdapat hubungan antara status pekerjaan dengan pemanfaatan puskesmas sebagai pelayanan primer di puskesmas Sidomulyo kota Bengkulu.

\section{DAFTAR PUSTAKA}

Data Laporan Penduduk. (2021). Data Laporan Penduduk Wilayah Sidomulyo Kota Bengkulu. Fatimah Siti, \& Indrawati Fitri. (2019). Faktor Pemanfaatan Pelayanan Kesehatan di Puskesmas. Higeia Journal of Public Health Research and Development, 1(3), 121-131. https://doi.org/https://doi.org/10.15294/higeia/ v3il/24747

Febriawati $\mathrm{H}$, Yanuarti $\mathrm{R}$, Oktarianita $\mathrm{O}$, Yandrizal Y, Angraini W. Tingkat Kualitas Pelayanan Di Puskesmas Betungan Kota Bengkulu Tahun 2020. Window of Health: Jurnal Kesehatan. 2021 Jul 25:261-71. https://doi.org/https://doi.org/10.33368/woh.v4 i03.685

Febriawati Henni, \& Yandrizal. (2019). Buku Manajemen dan Peran Puskesmas Sebagai Gatekeeper (hal. 198). Yogyakarta: Gosyen Publishing.

Kemenkes RI. (2014) Peraturan Menteri Kesehatan RI Nomor 75 Tahun 2014 Tentang Pusat Kesehatan Masyarakat. Jakarta : Kemenkes RI.

Kemenkes RI. (2015). Rencana strategis kementerian kesehatan tahun 20152019. Jakarta: Kementerian Kesehatan RI.

Kemenkes RI. (2020) Data Dasar Puskesmas Provinsi Bengkulu

Logen, Y., \& Balqis, D. (2015). Faktor yang berhubungan dengan Pemanfaatan Pelayanan Kesehatan oleh pemulung di TPA Tamangapa. Skripsi. Universitas Hasanudin.

Londo Jenry $P$, Tucunan Ardiansa A T, \& R Maramis Franckie R. (2017). Hubungan Antara Karakteristik Peserta Bpjs Kesehatan Dengan Pemanfaatan Pelayanan Puskesmas Di Wilayah Kerja Puskesmas Tahuna Barat. 
Kesmas,

6(3),

1-7.

https://ejournal.unsrat.ac.id/index.php/kesmas /article/view/22991

Napirah Ryman, Rahman Abd, T. A. (2016). Hubungan antara pendapatan dengan pemanfaatan pelayanan kesehatan di wilayah kerja Puskesmas Tambarana Kecamatan Poso Pesisir Utara Kabupaten Poso. Jurnal Pengembangan Kota, 4(1). https://doi.org/10.14710/jpk.4.1.29-39

Notoatmodjo, S. (2012). Pendidikan dan IImu Perilaku Kesehatan. Rineka Cipta.

Oktarianita, O., Febriawati $\mathrm{H}$, \& Kurniawan, D. (2020). Hubungan Strategi Bauran Pemasaran Dengan Loyalitas Pasien Rawat Jalan di RSUD Dr. M. Yunus Provinsi Bengkulu. Avicenna: Jurnal Ilmiah, 15(3), 198-205.

https://doi.org/10.36085/avicenna.v15i3.978

Rabbaniyah, F., \& Nadjib, M. (2019). Analisis Sosial Ekonomi dalam Pemanfaatan Fasilitas Kesehatan untuk Berobat Jalan di Provinsi Jawa Barat: Analisis Data Susenas Tahun 2017 Social Economic Analysis in Utilizing Health Facilities for Outpatient Treatment in West Java Province: Susenas Da. Jurnal MKMI, 15(1), 73-80. https://doi.org/http://dx.doi.org/10.30597/mkmi .v15i1.5888

Rahimah, R., Oktavidiati, E., Oktarianita, O., Febriawati, H., \& Sahputra, H. (2021). Hubungan Mutu Pelayanan Dengan Kepuasan Pasien di Poli Jantung Instalasi Rawat Jalan Rumah Sakit Umum Daerah (RSUD) Dr. M. Yunus Bengkulu. Jurnal Miracle, 1(1), 32-38. http://jurnal.umb.ac.id/index.php/miracle/articl e/view/669

Siswati, A. N., Sriatmi, A., \& Suryoputro, A. (2018). Hubungan Antara Karakteristik Masyarakat Dengan Pemanfaatan Pelayanan Imunisasi Pentavalen Booster Dalam Pencegahan Difteri Di Wilayah Kerja Puskesmas Halmahera Kota Semarang. Jurnal Kesehatan Masyarakat (Undip), 6(5), 26 - 32. Syarifain, A., Rumayar, A. A., Mandagi, C. K. F., Kesehatan, F., Universitas, M., \& Ratulangi, S. (2017). Hubungan Antara Pendidikan Dan
Pendapatan Dengan Pemanfaatan Pelayanan Kesehatan Oleh Pasien BPJS di Wilayah Kerja Puskesmas Sario Kota Manado. Kesmas, 6(4). https://ejournal.unsrat.ac.id/index.php/kesmas /article/view/23099

Wulandari, Citra, Ode, L., Imran, A., \& Syawal, A. (2016). Puskesmas Langara Kecamatan Wawonii Barat Kabupaten Konawe Kepulauan Tahun 2016. 1(3), 0-8. https://doi.org/10.37887/jimkesmas.v1i3.1087

Wulandari, F. K., \& Achadi, A. (2017). Analisis Karakteristik dan Persepsi Pengguna Pelayanan Terhadap Pemanfaatan Puskesmas Sebagai Gatekeeper di Dua Puskesmas Kota Bekasi Tahun 2016. Jurnal Ekonomi Kesehatan, 2(1), 39-47. https://doi.org/10.7454/eki.v2i1.1957 